INL/EXT-16-38289 Rev. 0

March 2016

\title{
Milestone report on MD potential development for uranium silicide
}

\author{
J. $Y \boldsymbol{u}$ \\ Y. Zhang \\ J. Hales
}

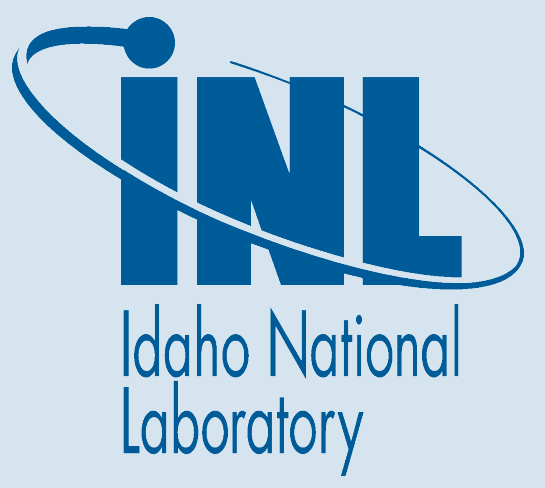




\section{NOTICE}

This information was prepared as an account of work sponsored by an agency of the U.S. Government. Neither the U.S. Government nor any agency thereof, nor any of their employees, makes any warranty, express or implied, or assumes any legal liability or responsibility for any third party's use, or the results of such use, of any information, apparatus, product, or process disclosed herein, or represents that its use by such third party would not infringe privately owned rights. The views expressed herein are not necessarily those of the U.S. Nuclear Regulatory Commission. 
INL/EXT-16-38289 Rev. 0

\title{
Milestone report on MD potential development for uranium silicide
}

\author{
J. $Y u$ \\ Y. Zhang \\ J. Hales
}

March 2016

\section{Idaho National Laboratory Fuel Modeling and Simulation Department \\ Idaho Falls, Idaho 83415}

Prepared for the

U.S. Department of Energy Office of Nuclear Energy

Under U.S. Department of Energy-Idaho Operations Office Contract DE-AC07-99ID13727 


\begin{abstract}
This report summarizes the progress on the interatomic potential development of triuranium-disilicide $\left(\mathrm{U}_{3} \mathrm{Si}_{2}\right)$ for molecular dynamics (MD) simulations. The development is based on the Tersoff type potentials for single element $\mathrm{U}$ and Si. The Si potential is taken from the literature and a Tersoff type $U$ potential is developed in this project. With the primary focus on the $\mathrm{U}_{3} \mathrm{Si}_{2}$ phase, some other U-Si systems such as $\mathrm{U}_{3} \mathrm{Si}$ are also included as a test of the transferability of the potentials for binary U-Si phases.

Based on the potentials for unary $\mathrm{U}$ and $\mathrm{Si}$, two sets of parameters for the binary U-Si system are developed using the Tersoff mixing rules and the cross-term fitting, respectively. The cross-term potential is found to give better results on the enthalpy of formation, lattice constants and elastic constants than those produced by the Tersoff mixing potential, with the reference data taken from either experiments or density functional theory (DFT) calculations. In particular, the results on the formation enthalpy and lattice constants for the $\mathrm{U}_{3} \mathrm{Si}_{2}$ phase and lattice constants for the high temperature $\mathrm{U}_{3} \mathrm{Si}\left(\mathrm{h}-\mathrm{U}_{3} \mathrm{Si}\right)$ phase generated by the cross-term potential agree well with experimental data. Reasonable agreements are also reached on the elastic constants of $\mathrm{U}_{3} \mathrm{Si}_{2}$, on the formation enthalpy for the low temperature $\mathrm{U}_{3} \mathrm{Si}\left(\mathrm{m}-\mathrm{U}_{3} \mathrm{Si}\right)$ and $\mathrm{h}-\mathrm{U}_{3} \mathrm{Si}$ phases, and on the lattice constants of $\mathrm{m}-\mathrm{U}_{3} \mathrm{Si}$ phase. All these phases are predicted to be mechanically stable.

The unary $U$ potential is tested for three metallic $U$ phases $(\alpha, \beta, \gamma)$. The potential is found capable to predict the cohesive energies well against experimental data for all three phases. It matches reasonably with previous experiments on the lattice constants and elastic constants of $\alpha \mathrm{U}$.
\end{abstract}




\section{Table of Contents}

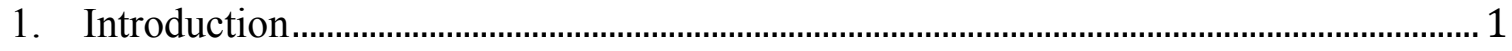

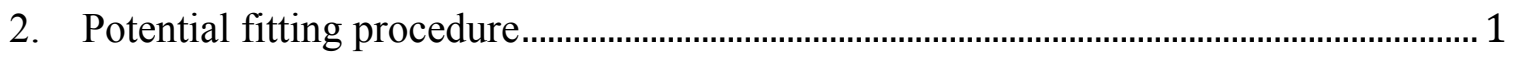

2.1 Potential formalism and fitting scheme …………...................................................... 1

2.2 Tersoff Potential .................................................................................................... 2

3. Assessment of fitting results............................................................................................. 4

3.1 Results for the Tersoff mixing potential .......................................................................... 4

3.1.1 $\mathrm{U}_{3} \mathrm{Si}_{2}$ phase ................................................................................................... 4

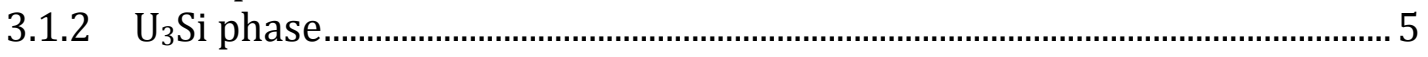

3.2 Results for the cross-term potential ......................................................................... 6

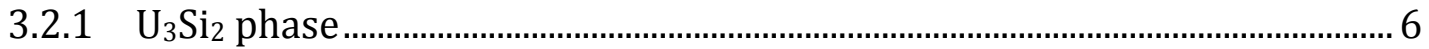

3.2.2 $\mathrm{U}_{3} \mathrm{Si}$ phase .....................................................................................................

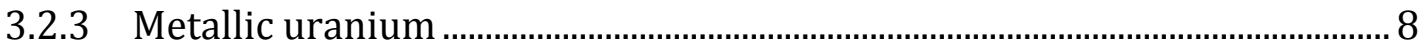

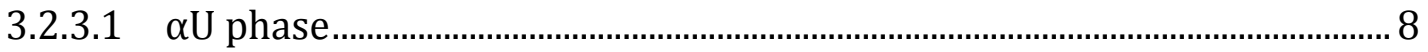

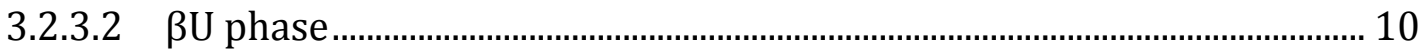

3.2.3.3 $\gamma \mathrm{U}$ phase ..................................................................................................... 10

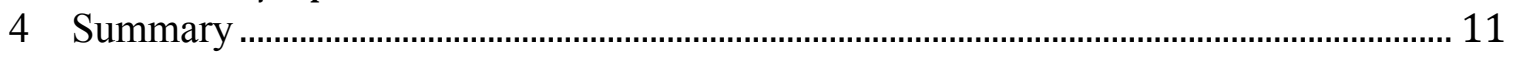

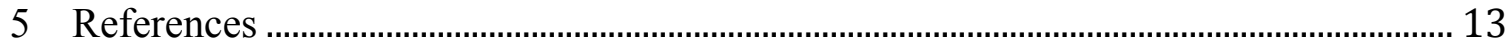




\section{Introduction}

The usage of triuranium-disilicide $\left(\mathrm{U}_{3} \mathrm{Si}_{2}\right)$ in place of uranium dioxide $\left(\mathrm{UO}_{2}\right)$ is one of the promising concepts proposed to increase the accident tolerance of nuclear fuels in light water reactors [1]. $\mathrm{U}_{3} \mathrm{Si}_{2}$ has higher thermal conductivities than that of $\mathrm{UO}_{2}$ at operating temperatures, resulting in lower fuel centerline temperatures. It also has a higher U density, which may enable some new cladding concepts that would otherwise require increased enrichment limits to compensate for their neutronic penalty. However, many materials properties of $\mathrm{U}_{3} \mathrm{Si}_{2}$ have not been determined and are required to have a good assessment of the in-reactor behavior of $\mathrm{U}_{3} \mathrm{Si}_{2}$. To mitigate the difficulties in getting all necessary data from experiments, atomistic calculations such as density-functionaltheory (DFT) calculations or molecular dynamics (MD) simulations are utilized and expected to generate needed data with better efficiency and reduced cost.

While DFT calculations are believed to be more accurate than MD simulations in general, their high computation cost strongly limits the length and time scales used in the calculations. In this accident tolerant fuel high-impact-problem (ATF-HIP) project, DFT calculations are used to obtain fundamental material properties in bulk $\mathrm{U}_{3} \mathrm{Si}_{2}$. These data will also be used to assist the development and the assessment of an U-Si interatomic potential, which will be used in MD simulations for material issues involving extended lattice defects such as grain boundaries, radiation induced defect clusters, and their interactions. In the following, the development of a Tersoff type U-Si potential is described. We start with the introduction of potential fitting procedure in Section 2 and proceed with the potential parameters and fitting results in Section 3. A summary is given in Section 4.

\section{Potential fitting procedure}

\subsection{Potential formalism and fitting scheme}

To fit an interatomic potential, a formalism needs to be decided considering the bonding nature in the material system and the material properties of interest. In U-Si systems, the bonding nature is primarily metallic, with possibly covalent and ionic contributions as well. While being used in reactors, there are several phenomena that are of particular interest: 1) the production of lattice defects by neutron irradiation and their interaction with interfaces such as grain boundaries and their evolution; 2) the interaction between fission gas atoms with lattice defects and interfaces; and 3) phase transformation in the fuels induced by the changes in temperature and chemical composition. For instance, in freshly fabricated $\mathrm{U}_{3} \mathrm{Si}_{2}$ fuels there are usually secondary phases such as $\mathrm{U}_{3} \mathrm{Si}$ and/or USi [2]. Furthermore, silicide compounds $\left(\mathrm{U}_{3} \mathrm{Si}_{2}\right.$ and $\left.\mathrm{U}_{3} \mathrm{Si}\right)$ are known to become amorphous under irradiation at low temperatures [2-4]. Based on the above considerations, the Tersoff type bond-order formalism [5,6] is selected as it can treat both metallic and covalent bonding. A Tersoff type Si potential existing in the literature has been shown to describe liquid and amorphous Si phases well, as well as other crystallographic phases of 
$\mathrm{Si}$ [7-9]. Therefore, this Si potential is used here to describe the Si-Si interaction in U-Si systems. However, so far there have been no Tersoff type U potentials that can describe all possible $U$ phases, $\alpha, \beta$, and $\gamma$. To come up with a U-Si potential, we start with the development of a Tersoff type U potential. Based on the existing Si and the U potential developed here, cross-term parameters for U-Si interactions are fitted for binary U-Si phases including $\mathrm{U}_{3} \mathrm{Si}_{2}$ and $\mathrm{U}_{3} \mathrm{Si}$. During the fitting, we focus on the $\mathrm{U}_{3} \mathrm{Si}_{2}$ phase, which is the primary fuel candidate of our ATF-HIP project.

In MD simulations it is desired to capture both the thermodynamic and the kinetic properties. This sets a high standard for the interatomic potentials used in the simulations, for instance potentials that are fit by force matching with input data such as lattice, energy and force directly from first-principles DFT calculations. The software POTFIT $[10,13-14]$ is suitable for potential fitting using force matching, and it was initialy utilized here. Though using POTFIT to develop the potential is very promising, the fidelity of the fitted potential crucially depends on the reliability of the forces from DFT calculations. However, it was observed that in our DFT calculations $\gamma$-U experienced a $\mathrm{BCC}$ to $\mathrm{BCT}$ transition, leading to suspicion that the forces from the standard DFT calculations may have contributed to destabilize $\gamma$-U. It is further evident from the unexpected low specific heat capacity, $\mathrm{C}_{\mathrm{v}}$, of $\gamma-\mathrm{U}$ predicted by the DFT calculations that the forces calculated by DFT could be erroneous. This error was likely due to the limitation of traditional DFT method to handle the $5 \mathrm{f}$-orbitals of metal $\mathrm{U}$, which combines strong electron correlation, multi-minima, relativistic effects of $5 \mathrm{f}$-orbitals and $5 \mathrm{f}$ electron delocalization/hybridization. Thus it is determined not viable to fit the U-Si potential using the force matching potential fitting package POTFIT.

Without taking force information into the collective dataset, the software GULP [11, 12] is used to fit the binary U-Si potential. GULP directly fits materials properties such as lattice parameters, total potential energies (based on cohesive or formation energies) and elastic constants of targeting crystal structures or phases. Note that GULP is not a force matching potential fitting package, in contrast to POTFIT. During fitting, we take the data from previous experiments [13, 14] and a recent DFT calculation [15] as reference. The fitting procedure can be extended in the future by including more data that will be available in the near future, for instance, those that will be generated within the same ATF-HIP project.

Here the primary goal is to develop a binary U-Si potential for the $\mathrm{U}_{3} \mathrm{Si}_{2}$ phase. As a good Tersoff type $U$ potential does not exist, we start with the fitting of the $U$ interatomic potential. While focusing on the $\mathrm{U}_{3} \mathrm{Si}_{2}$ phase, we also try to pursue the transferability so that the potential can be used to study secondary phases, such as $(\alpha, \beta, \gamma)-\mathrm{U}$ and $\mathrm{U}_{3} \mathrm{Si}$.

\subsection{Tersoff Potential}

In the Tersoff formalism [5, 6], the total potential energy of a material system, $E$, is defined as the summation of pair interactions $V_{i j}$ :

$$
E=\frac{1}{2} \sum_{j \neq i} V_{i j}
$$


with $V_{i j}$ given by the following equations:

$$
\begin{gathered}
V_{i j}=f_{C}\left(r_{i j}\right)\left[f_{R}\left(r_{i j}\right)+b_{i j} f_{A}\left(r_{i j}\right)\right] \\
f_{C}(r)=\left\{\begin{array}{cc}
1 & r<R-D \\
\frac{1}{2}-\frac{1}{2} \sin \left(\frac{\pi}{2} \frac{r-R}{D}\right): R-D<r<R+D \\
: r>R+D \\
f_{R}(r)=A e^{\left(-\lambda_{1} r\right)} \\
f_{A}(r)=A e^{\left(-\lambda_{2} r\right)}
\end{array}\right. \\
b_{i j}=\sum_{k \neq i, j} f_{C}\left(r_{i j}\right) g\left(\theta_{i j k}\right) e^{\left[\lambda_{3}^{m}\left(r_{i j}-r_{i k}\right)^{m}\right]} \\
g(\theta)=1+\frac{c^{2}}{d^{2}}-\frac{c^{2}}{\left[d^{2}+(h-\cos \theta)^{2}\right]}
\end{gathered}
$$

Here, $r_{i j}$ is the distance between atoms $i$ and $j ; f_{A}$ and $f_{R}$ are the attractive three-body interactions and repulsive pair term, respectively; and $f_{C}$ is a smooth cutoff function. The term $\zeta_{i j}$ defines the effective coordination number of atom $i$, i.e., the effective number of nearest neighbors, in which the relative distance of two neighbors $r_{i j}-r_{i k}$ and the bondangle $\theta$ are taken into account. With a minimum at $h=\cos \theta$ in the function $g(\theta)$, the parameter $d$ determines the curvature or sharpness, and $c$ expresses the strength of the angular effect. The summations in the formula are over all neighbors $j$ and $k$ of atom $i$ within the cutoff distance $\mathrm{R}+\mathrm{D}$.

To fit a unary $U$ potential, the lattice constants and cohesive energies of all three $U$ phases are included in the fitting. The elastic constants of $\alpha \mathrm{U}$ are also used in the fitting. The thus obtained parameters for U-U interaction are listed in Table 1.

Based on the existing unary $\mathrm{Si}$ potential [5] and the unary $U$ interatomic potential developed here, the interaction between $\mathrm{U}$ atoms and $\mathrm{Si}$ atoms can be obtained in two ways. The first is to fit all the cross-term parameters using the experimental and/or DFT data. The thus obtained potential is referred to as the cross-term potential. The second is to calculate these parameters using the Tersoff mixing rule [6], with the resulting potential being the Tersoff mixing potential. The parameters for U-Si terms using the cross-term fitting are listed in Table I. For Tersoff mixing potential, the following U-Si parameters are needed:

$$
\begin{aligned}
\lambda_{1}^{S i, U} & =\frac{1}{2}\left(\lambda_{1}^{S i}+\lambda_{1}^{U}\right) \\
\lambda_{12}^{S i, U} & =\frac{1}{2}\left(\lambda_{2}^{S i}+\lambda_{2}^{U}\right) \\
A_{S i, U} & =\chi_{1}\left(A_{S i} A_{U}\right)^{1 / 2} \\
B_{S i, U} & =\chi_{2}\left(B_{S i} B_{U}\right)^{1 / 2} \\
L & =\left(L_{S i} L_{U}\right)^{1 / 2} \\
S & =\left(S_{S i} S_{U}\right)^{1 / 2}
\end{aligned}
$$


where $L=R+D$ and $S=R-D \cdot \chi_{1}$ and $\chi_{2}$ are parameters for the fine adjustment of the simple interpolation to describe the strength of the heteropolar bond between $U$ atom and $\mathrm{Si}$ atom. They are the only two parameters $\left(\chi_{1}\right.$ and $\left.\chi_{2}\right)$ to be fitted and their values are 1.1366 and 0.8056 , respectively.

Table I. Parameters for uranium, silicon, and the cross term of U-Si. R and D were not systematically optimized and $\mathrm{m}$ is fixed to 3 . The Si parameters are taken from literature [5].

\begin{tabular}{cccc}
\hline & $\mathrm{Si}$ & $\mathrm{U}$ & $\mathrm{Si}-\mathrm{U}$ \\
\hline $\mathrm{A}(\mathrm{eV})$ & 1830.8 & 540.8202 & 556.45915 \\
$\mathrm{~B}(\mathrm{eV})$ & 471.18 & 179.4814 & 178.8864 \\
$\lambda_{1}\left(\AA^{-1}\right)$ & 2.4799 & 1.8333 & 1.82328 \\
$\lambda_{2}\left(\AA^{-1}\right)$ & 1.7322 & 1.1989 & 1.26005 \\
$\beta$ & 0.0000010999 & 0.0000010999 & 0.000001 \\
$\mathrm{~m}$ & 3 & 3 & 3 \\
$\mathrm{n}$ & 0.78734 & 0.78812 & 2.27619 \\
$\mathrm{c}$ & 100390.0 & 95575.5 & 148153. \\
$\mathrm{~d}$ & 16.218 & 16.15206 & 29.6570 \\
$\mathrm{~h}$ & -0.59826 & -0.7168 & -2.98962 \\
$\lambda_{3}\left(\AA^{-1}\right)$ & 1.7322 & 1.742313 & 1.64540 \\
$\mathrm{R}(\AA)$ & 2.85 & 3.425 & 3.425 \\
$\mathrm{D}(\AA)$ & 0.15 & 0.225 & 0.225 \\
\hline
\end{tabular}

\section{Assessment of fitting results}

\subsection{Results for the Tersoff mixing potential}

\subsubsection{U3Si2 phase}

The $\mathrm{U}_{3} \mathrm{Si}_{2}$ phase is the primary focus in this study. Table II lists the calculated material properties of the $\mathrm{U}_{3} \mathrm{Si}_{2}$ phase using the Tersoff mixing potential, compared with the data from either experiments such as the lattice constants $(\AA)$ [13] and the potential energy $(\mathrm{eV})$ (derived from the formation energy from Ref. [14]) or DFT calculations of the elastic constants (GPa) [15].

The lattice constants of $a, b$, and $c$ from the Tersoff mixing potential are $7.124 \AA, 7.124$ $\AA$, and $3.789 \AA$, respectively. These results agree well with the experimental data [13] with the fitting errors below 3\%. More specifically, the errors for the lattice constants of $a, b$, and $c$ are $-2.9 \%,-2.9 \%$, and $-2.37 \%$, respectively.

The crystal structure of $\mathrm{U}_{3} \mathrm{Si}_{2}$ is tetragonal with the space group P4/mbm (127) [13], in which the lattice constants of $a$ and $b$ should be equal. However, such criteria may not be always satisfied after the structure is full relaxed without symmetry constraints. In the fitting, $a$ and $b$ are allowed to change independently to avoid the appearance of 
metastable phases. For this reason, both $a$ and $b$ are listed in the table for the comparison with experimental data.

With the targeting potential energy of $-52.53 \mathrm{eV}$ for $\mathrm{U}_{3} \mathrm{Si}_{2}$ (10 atoms per unit cell), the calculated total potential energy is $-55.939 \mathrm{eV}$. The corresponding error is $\sim 6.5 \%$. The corresponding enthalpy of reaction is predicted to be exothermic, which is consistent with the experimental observations in Ref. [14].

As listed in Table II, all elastic constants are significantly over predicted in reference to DFT results. An attempt to improve the elastic constants for the $\mathrm{U}_{3} \mathrm{Si}_{2}$ phase leads to further deviations of the predicted energy and lattice constants from the DFT results.

Table II. Calculated material properties of $\mathrm{U}_{3} \mathrm{Si}_{2}$ and $\mathrm{U}_{3} \mathrm{Si}$ phases using the Tersoff mixing rules, compared with the dataset from either experiment such as the lattice constants $(a, b, c$, in $\AA$ ) [13] and cohesive energy $E(\mathrm{eV})$ [14] or DFT calculations of the elastic constants $C_{i j}$ (GPa) [15].

\begin{tabular}{cccccc}
\hline \hline Atoms/UC & $\mathrm{Phase}$ & Type & Exp./DFT & Ca. & Error(\%) \\
\hline 10 & $\mathrm{U}_{3} \mathrm{Si}_{2}$ & $\mathrm{C}_{11}$ & 167.26 & 771.662 & 361.35 \\
10 & $\mathrm{U}_{3} \mathrm{Si}_{2}$ & $\mathrm{C}_{33}$ & 205.31 & 525.819 & 156.11 \\
10 & $\mathrm{U}_{3} \mathrm{Si}_{2}$ & $\mathrm{C}_{12}$ & 45.63 & 217.364 & 376.36 \\
10 & $\mathrm{U}_{3} \mathrm{Si}_{2}$ & $\mathrm{C}_{13}$ & 50.34 & 355.676 & 606.55 \\
10 & $\mathrm{U}_{3} \mathrm{Si}_{2}$ & $\mathrm{C}_{44}$ & 67.49 & 502.568 & 644.66 \\
10 & $\mathrm{U}_{3} \mathrm{Si}_{2}$ & $\mathrm{C}_{66}$ & 74.09 & 454.232 & 513.08 \\
10 & $\mathrm{U}_{3} \mathrm{Si}_{2}$ & $\mathrm{E}$ & -52.53 & -55.939 & 6.49 \\
10 & $\mathrm{U}_{3} \mathrm{Si}_{2}$ & $\mathrm{a}$ & 7.3364 & 7.124 & -2.90 \\
10 & $\mathrm{U}_{3} \mathrm{Si}_{2}$ & $\mathrm{~b}$ & 7.3364 & 7.124 & -2.90 \\
10 & $\mathrm{U}_{3} \mathrm{Si}_{2}$ & $\mathrm{c}$ & 3.89 & 3.798 & -2.37 \\
4 & $\mathrm{~h}-\mathrm{U}_{3} \mathrm{Si}$ & $\mathrm{E}$ & -20.51 & -24.529 & 19.60 \\
4 & $\mathrm{~h}-\mathrm{U}_{3} \mathrm{Si}$ & $\mathrm{a}$ & 4.346 & 4.164 & -4.19 \\
4 & $\mathrm{~h}-\mathrm{U}_{3} \mathrm{Si}$ & $\mathrm{b}$ & 4.346 & 4.164 & -4.19 \\
4 & $\mathrm{~h}-\mathrm{U}_{3} \mathrm{Si}$ & $\mathrm{c}$ & 4.346 & 4.164 & -4.19 \\
16 & $\mathrm{~m}-\mathrm{U}_{3} \mathrm{Si}$ & $\mathrm{E}$ & -86.15 & -98.118 & 13.89 \\
16 & $\mathrm{~m}-\mathrm{U}_{3} \mathrm{Si}$ & $\mathrm{a}$ & 6.029 & 5.89 & -2.31 \\
16 & $\mathrm{~m}-\mathrm{U}_{3} \mathrm{Si}$ & $\mathrm{b}$ & 6.029 & 5.89 & -2.31 \\
16 & $\mathrm{~m}-\mathrm{U}_{3} \mathrm{Si}$ & $\mathrm{c}$ & 8.696 & 8.329 & -4.22 \\
\hline \hline
\end{tabular}

\subsection{2 $\mathrm{U}_{3} \mathrm{Si}$ phase}

There are two phases for $\mathrm{U}_{3} \mathrm{Si}$ : $\mathrm{m}-\mathrm{U}_{3} \mathrm{Si}$ (space group $\mathrm{I} 4 / \mathrm{mcm}$ (140) and 16 atoms per unit cell) at low temperature and $\mathrm{h}-\mathrm{U}_{3} \mathrm{Si}$ (space group $\mathrm{Pm} 3 \mathrm{~m}$ (221) and 4 atoms per unit cell) at high temperature [13]. As listed in Table II, the lattice constants given by the Tersoff mixing potential agree well with experimental data [13] for both phases of $\mathrm{U}_{3} \mathrm{Si}$. Specially, the lattice constant for $\mathrm{h}-\mathrm{U}_{3} \mathrm{Si}$ is $4.164 \AA$, corresponding to an error of about $4.19 \%$. The cubic structure is maintained after being fully relaxed. The lattice constants 
$a, b$, and $c$ for $\mathrm{m}-\mathrm{U}_{3} \mathrm{Si}$ are $5.89 \AA, 5.89 \AA$, and $8.329 \AA$, respectively. The tetragonal structure is kept and the discrepancies for the lattice constants of $a, b$, and $c$ from the experiments are $-2.31 \%,-2.31 \%$ and $-4.22 \%$, respectively.

The total potential energies from the prediction and experiment for $\mathrm{m}-\mathrm{U}_{3} \mathrm{Si}$ are -98.118 $\mathrm{eV}$ and $-86.15 \mathrm{eV}$, respectively, with an error $\sim 13.89 \%$. The corresponding enthalpy of reaction is predicted to be exothermic, which is consistent with the experimental observation in Ref. [14].

The elastic constants are not tested for both $\mathrm{U}_{3} \mathrm{Si}$ phases. In an attempt to further reduce the error in the potential energies of $h-\mathrm{U}_{3} \mathrm{Si}_{2}$ and $\mathrm{m}-\mathrm{U}_{3} \mathrm{Si}$, the discrepancies of the predicted elastic constants for $\mathrm{U}_{3} \mathrm{Si}_{2}$ with respect to the DFT results are found to increase.

In summary, the lattice constants and formation enthalpy for the $\mathrm{U}_{3} \mathrm{Si}_{2}$ phase and two $\mathrm{U}_{3} \mathrm{Si}$ phases predicted by the Tersoff mixing potential are in good agreement with the experimental data. However, the elastic constants for $\mathrm{U}_{3} \mathrm{Si}_{2}$ are significantly over estimated.

\subsection{Results for the cross-term potential}

\subsection{1 $\mathrm{U}_{3} \mathrm{Si}_{2}$ phase}

Table III lists the calculated material properties of the $\mathrm{U}_{3} \mathrm{Si}_{2}$ and $\mathrm{U}_{3} \mathrm{Si}$ phases using the parameters listed in Table I, compared with the data from either experiment such as the lattice constants $(\AA)$ [13] and the total potential energy (eV) [14] or DFT calculations of the elastic constants $(\mathrm{GPa})[15]$.

The lattice constants of $a, b$, and $c$ for $\mathrm{U}_{3} \mathrm{Si}_{2}$ from the developed potential are $7.298 \AA$, $7.298 \AA$, and $3.899 \AA$, respectively. The agreement between the potential prediction and the experimental data [13] is excellent, with the errors being less than $1 \%$. Specially, the errors for the lattice constants of $a, b$, and $c$ are $-0.52 \%,-0.52 \%$, and $0.23 \%$, respectively. The deviation of the predicted volume $\left(207.67 \AA^{3}\right.$ per unit cell) from the experimental value $\left(209.37 \AA^{3}\right.$ per unit cell) is only about $-0.815 \%$.

The total potential energies from the prediction and experiment are $-52.545 \mathrm{eV}$ and $52.53 \mathrm{eV}$, respectively, giving an negligible error of $-0.015 \mathrm{eV}$, or an relative error of $\sim 0.03 \%$. The corresponding enthalpy of reaction is predicted to be exothermic, in agreement with the experimental observation in Ref. [14].

As listed in Table III, all elastic constants are overly predicted but significantly improved compared with the results obtained using the Tersoff mixing potential. In the attempt to reduce the error on the elastic constants for the $\mathrm{U}_{3} \mathrm{Si}_{2}$ phase, the errors on the potential energies and lattice constants are found to increase. This indicates that some balance is needed between the accuracies of different properties. The current potential paramters are chosen to give the enthalpy of formation correctly and to match the lattice constants as best as possible for the $\mathrm{U}_{3} \mathrm{Si}_{2}$ phase, with an acceptable level of accuracy for the elastic constants. 
Table III. Calculated material properties of $\mathrm{U}_{3} \mathrm{Si}_{2}$ and $\mathrm{U}_{3} \mathrm{Si}$ phases using the parameters listed in the Table I, compared with the dataset from either experiment such as the lattice constants $(a, b, c$, in $\AA$ ) [13] and total potential energy $E(\mathrm{eV})$ [14] or DFT calculations of the elastic constants $C_{i j}$ (GPa) [15].

\begin{tabular}{cccccc}
\hline \hline Atoms/UC & $\mathrm{Phase}_{10}$ & Type & Exp./DFT & Ca. & Error(\%) \\
\hline 10 & $\mathrm{U}_{3} \mathrm{Si}_{2}$ & $\mathrm{C}_{11}$ & 167.26 & 249.801 & 49.35 \\
10 & $\mathrm{U}_{3} \mathrm{Si}_{2}$ & $\mathrm{C}_{33}$ & 205.31 & 221.611 & 7.94 \\
10 & $\mathrm{U}_{3} \mathrm{Si}_{2}$ & $\mathrm{C}_{12}$ & 45.63 & 120.439 & 163.95 \\
10 & $\mathrm{U}_{3} \mathrm{Si}_{2}$ & $\mathrm{C}_{13}$ & 50.34 & 154.813 & 207.53 \\
10 & $\mathrm{U}_{3} \mathrm{Si}_{2}$ & $\mathrm{C}_{44}$ & 67.49 & 109.251 & 61.88 \\
10 & $\mathrm{U}_{3} \mathrm{Si}_{2}$ & $\mathrm{C}_{66}$ & 74.09 & 102.274 & 38.04 \\
10 & $\mathrm{U}_{3} \mathrm{Si}_{2}$ & $\mathrm{E}$ & -52.53 & -52.545 & 0.03 \\
10 & $\mathrm{U}_{3} \mathrm{Si}_{2}$ & $\mathrm{a}$ & 7.3364 & 7.298 & -0.52 \\
10 & $\mathrm{U}_{3} \mathrm{Si}_{2}$ & $\mathrm{~b}$ & 7.3364 & 7.298 & -0.52 \\
10 & $\mathrm{U}_{3} \mathrm{Si}_{2}$ & $\mathrm{c}$ & 3.89 & 3.899 & 0.23 \\
4 & $\mathrm{~h}-\mathrm{U}_{3} \mathrm{Si}$ & $\mathrm{E}$ & -20.51 & -22.218 & 8.33 \\
4 & $\mathrm{~h}-\mathrm{U}_{3} \mathrm{Si}$ & $\mathrm{a}$ & 4.346 & 4.381 & 0.81 \\
4 & $\mathrm{~h}-\mathrm{U}_{3} \mathrm{Si}$ & $\mathrm{b}$ & 4.346 & 4.381 & 0.81 \\
4 & $\mathrm{~h}-\mathrm{U}_{3} \mathrm{Si}$ & $\mathrm{c}$ & 4.346 & 4.381 & 0.81 \\
16 & $\mathrm{~m}-\mathrm{U}_{3} \mathrm{Si}$ & $\mathrm{E}$ & -86.15 & -88.872 & 3.16 \\
16 & $\mathrm{~m}-\mathrm{U}_{3} \mathrm{Si}$ & $\mathrm{a}$ & 6.029 & 6.196 & 2.77 \\
16 & $\mathrm{~m}-\mathrm{U}_{3} \mathrm{Si}$ & $\mathrm{b}$ & 6.029 & 6.196 & 2.77 \\
16 & $\mathrm{~m}-\mathrm{U}_{3} \mathrm{Si}$ & $\mathrm{c}$ & 8.696 & 8.762 & 0.76 \\
\hline \hline
\end{tabular}

\subsection{2 $\mathrm{U}_{3} \mathrm{Si}$ phase}

The lattice constants from the cross-term potential agree well with the experimental values [13] for both $h-U_{3} S i$ and $m-U_{3} S i$ phases. Specially, the lattice constants for the h$\mathrm{U}_{3} \mathrm{Si}$ ( 4 atoms per unit cell) phase is $4.381 \AA$, corresponding to an error of only $-0.81 \%$ in reference to the experimental value of $4.346 \AA$. The cubic symmetry is maintained after being fully relaxed. The error of the predicted volume $\left(84.09 \AA^{3}\right.$ per unit cell $)$ in reference to the experimental value ( $82.09 \AA^{3}$ per unit cell) for the $\mathrm{h}-\mathrm{U}_{3} \mathrm{Si}$ phase is about $2.436 \%$.

The cubic h- $\mathrm{U}_{3} \mathrm{Si}$ structure is metastable when the temperature is below $780{ }^{\circ} \mathrm{C}$ [13] and will transform to the tetragonal $\mathrm{m}-\mathrm{U}_{3} \mathrm{Si}$ phase. As listed in the Table III, the lattice constants of $a, b$, and $c$ for the $\mathrm{m}-\mathrm{U}_{3} \mathrm{Si}$ (16 atoms per unit cell) phase are $6.196 \AA, 6.196$ $\AA$, and $8.762 \AA$, respectively. The tetragonal structure is kept and the deviation of $a, b$, and $c$ from the experimental results are $2.77 \%, 2.77 \%$, and $0.76 \%$, respectively. The error of the predicted volume (336.377 $\AA^{3}$ per unit cell) against the experiment value (316.09 $\AA^{3}$ per unit cell) for the $\mathrm{m}-\mathrm{U}_{3} \mathrm{Si}$ state is about $6.418 \%$. 
With the targeting potential energy of $-86.15 \mathrm{eV}$ for the $\mathrm{m}-\mathrm{U}_{3} \mathrm{Si}$ phase, the value predicted by the cross-term potential is $-88.872 \mathrm{eV}$, with a relative error of $3.16 \%$. The predicted enthalpy of reaction is also exothermic, which is consistent with the experimental observation [14].

The elastic constants are not tested for both phases of $\mathrm{U}_{3} \mathrm{Si}$. We have attempted to improve the potential performance on $\mathrm{U}_{3} \mathrm{Si}$ phases regarding the energy and elastic constants. However, this requires a significant sacrifice in the performance for $\mathrm{U}_{3} \mathrm{Si}_{2}$, which is the primary focus.

In summary, the lattice constants and structure volume for the $\mathrm{U}_{3} \mathrm{Si}_{2}$ phase and two $\mathrm{U}_{3} \mathrm{Si}$ phases predicted by the cross-term potential are in excellent agreement with the experimental data. Compared with the Tersoff mixing potential, significant improvement has been noticed on the elastic constants of $\mathrm{U}_{3} \mathrm{Si}_{2}$. Improvement is also observed regarding the lattice constants and the enthalpy of formation. Such improvements are likely related to the fact that for the cross-term potential, more parameters are fitted from experimental or DFT data.

\subsubsection{Metallic uranium}

Metallic uranium has three solid phases: $\alpha$ (face-centered orthorhombic), $\beta$ (tetragonal) and $\gamma$ (body-centered cubic (bcc) [16]. Upon increasing temperature, uranium transforms from $\alpha$ to $\beta$ [17] at approximately $935 \mathrm{~K}$ and $\beta$ transforms to $\gamma$ at approximately $1045 \mathrm{~K}$ [18]. The transferibility and the accuracy of the unary $U$ potential are tested for all three phases, $\alpha, \beta$, and $\gamma$. Table IV lists the calculated material properties of $\alpha, \beta$, and $\gamma-U$ using the parameters listed in Table I. During the potential fitting procedure, the data regarding the phase order is aligned with the structure stability in uranium according to Ref. [18, 19]. The corresponding potential energies for $\beta$ and $\gamma$ phases are derived from our DFT calculations and data collected in Ref. [20], respectively.

For the $\alpha \mathrm{U}$ phase, the data is taken from previous experiments on the lattice constants $(\AA)$ [21], the total potential energy (eV) (based on the cohesive energy from Ref. [22]), and the elastic constants $(\mathrm{GPa})$ at $0 \mathrm{~K}$ [23] from a linear extrapolation of experimental observation [24]. For the $\beta U$ phase, the lattice constants are from experimental measurements in Ref. [17]. For the $\gamma \mathrm{U}$ phase, the lattice constant is from the experiment in Ref [25] at room temperature, $298 \mathrm{~K}$.

\subsubsection{1 $\alpha \mathrm{U}$ phase}

For uranium metal, the ground state is the orthorhombic $\alpha$-phase, with space group of Cmcm (\#63) [21]. It is stable up to $935 \mathrm{~K}$ at ambient pressure [16]. The lattice constants of $a, b$, and $c$ for the $\alpha \mathrm{U}$ phase are predicted to be $3.125 \AA, 5.413 \AA$, and $5.103 \AA$, respectively. The agreement between the predictions and the experimental data [21] is reasonable with the errors being less than $10.2 \%$. Specially, the errors for $a, b$, and $c$ are $10.19 \%,-7.74 \%$, and $3.4 \%$, respectively. The deviation of the predicted volume $(86.32$

$\AA^{3}$ per unit cell) from the experimental value $\left(82.11 \AA^{3}\right.$ per unit cell) for the $\alpha U$ phase is 
about $5.12 \%$. The total potential energies for the 4-atom unit cell of $\alpha \mathrm{U}$ given by the potential is $-22.32 \mathrm{eV}$, in reference to a value of $-22.2 \mathrm{eV}$ derived from the experimental cohesive energy ( $-5.55 \mathrm{eV} /$ atom) from Ref. [22], with a negligible error of $0.54 \%$.

As listed in Table IV, all elastic constants are under-estimated except for $\mathrm{C}_{12}$. Further improvement on the elastic constants requires some sacrifice in the accuracies regarding the energy and lattice constants. Another attempt to reduce the error of the lattice constants for $\alpha \mathrm{U}$ lead to a deviation of relative phase order in reference to that in Ref. [18], and an increase in the errors for the energy and lattice constants.

Table IV. Calculated material properties of the three $U$ phases of $(\alpha, \beta, \gamma)$, using the parameters listed in Table I for U, compared with the dataset from either experiment or DFT calculations. For the $\alpha U$ phase, the data are included the lattice constants $(\AA)$ [21] and the total potential energy (eV) (based on the cohesive energy from Ref. [22]) and the elastic constants (GPa) at 0K [23] from a linear extrapolation of experimental observation [24]. For the $\beta U$ phase, the lattice constants are from experiments in Ref. [17]. For the $\gamma U$ phase, the lattice constants are from experiments in Ref [25] at 298K. The potential energies for $\beta$ and $\gamma$ phases are derived from the data collected in Ref. [20], in which the phase order is aligned with the structure stability in uranium in Ref [18].

\begin{tabular}{cccccc}
\hline \hline Atoms/UC & Phase & Type & Exp./DFT & Ca. & Error(\%) \\
\hline 4 & $\alpha U$ & $\mathrm{C}_{11}$ & 210 & 177.1 & -15.67 \\
4 & $\alpha \mathrm{U}$ & $\mathrm{C}_{22}$ & 215 & 177.08 & -17.64 \\
4 & $\alpha \mathrm{U}$ & $\mathrm{C}_{33}$ & 297 & 190.13 & -35.98 \\
4 & $\alpha \mathrm{U}$ & $\mathrm{C}_{44}$ & 145 & 49.21 & -66.06 \\
4 & $\alpha \mathrm{U}$ & $\mathrm{C}_{55}$ & 94 & 49.21 & -47.65 \\
4 & $\alpha \mathrm{U}$ & $\mathrm{C}_{66}$ & 87 & 55.45 & -36.26 \\
4 & $\alpha \mathrm{U}$ & $\mathrm{C}_{12}$ & 46 & 66.17 & 43.85 \\
4 & $\alpha \mathrm{U}$ & $\mathrm{C}_{13}$ & 21 & 53.14 & 153.05 \\
4 & $\alpha \mathrm{U}$ & $\mathrm{E}$ & -22.2 & -22.32 & 0.54 \\
4 & $\alpha \mathrm{U}$ & $\mathrm{a}$ & 2.836 & 3.125 & 10.19 \\
4 & $\alpha \mathrm{U}$ & $\mathrm{b}$ & 5.867 & 5.413 & -7.74 \\
4 & $\alpha \mathrm{U}$ & $\mathrm{c}$ & 4.935 & 5.103 & 3.40 \\
30 & $\beta \mathrm{U}$ & $\mathrm{E}$ & -163.413 & -164.49 & 0.66 \\
30 & $\beta \mathrm{U}$ & $\mathrm{a}$ & 10.759 & 10.322 & -4.06 \\
30 & $\beta \mathrm{U}$ & $\mathrm{b}$ & 10.759 & 10.714 & -0.42 \\
30 & $\beta \mathrm{U}$ & $\mathrm{c}$ & 5.653 & 5.745 & 1.63 \\
2 & $\gamma \mathrm{U}$ & $\mathrm{E}$ & -10.339 & -10.973 & 6.13 \\
2 & $\gamma \mathrm{U}$ & $\mathrm{a}$ & 3.47 & 3.474 & 0.12 \\
2 & $\gamma \mathrm{U}$ & $\mathrm{b}$ & 3.47 & 3.474 & 0.12 \\
2 & $\gamma \mathrm{U}$ & $\mathrm{c}$ & 3.47 & 3.474 & 0.12 \\
\hline \hline
\end{tabular}




\subsubsection{2 $\beta \mathrm{U}$ phase}

$\beta$ phase, with centro-symmetric space group $\mathrm{P} 4_{2} / \mathrm{mnm}^{(\# 136)}$ [17], is stable from 935 to $1045 \mathrm{~K}[16,19]$ for pressures up to $3 \mathrm{GPa}[26]$. It has a very complicated tetragonal structure with 30 atoms per primitive cell (PC). As listed in Table IV, the predicted lattice constants $a, b$, and $c$ of $\beta \mathrm{U}$ are $10.322 \AA, 10.714 \AA$, and $5.745 \AA$, respectively. Note that the tetragonal structure is unstable and transfers to an orthorhombic structure after full structure relaxation. The discrepancies of $a, b$, and $c$ with respect to the experiment values given in Ref. [17] are $-4.06 \%,-0.42 \%$, and $1.63 \%$, respectively. The error of the predicted volume $\left(635.339 \AA^{3}\right.$ per unit cell) in reference to the experiment value $(654.369$ $\AA^{3}$ per unit cell) is about $2.908 \%$.

With the targeting potential energy of $-163.413 \mathrm{eV}$ (corresponding to a cohesive energy of $-5.447 \mathrm{eV} /$ atom, shifting up those of the $\alpha \mathrm{U}$ phase by $0.103 \mathrm{eV} /$ atom according to our DFT calculations), the total potential energy given by the potential is $-164.49 \mathrm{eV}$. The corresponding error is $0.66 \%$. The predicted cohesive energy of $-5.483 \mathrm{eV} /$ atom is shifted up by $0.097 \mathrm{eV} /$ atom with respect to $\alpha \mathrm{U}$. Thus the right phase order between $\alpha \mathrm{U}$ and $\beta \mathrm{U}$ is attained. The elastic constants are not tested for the $\beta U$ phase.

In an attempt to reduce the error on the lattice constants for $\beta U$, the error on the cohesive energy worsens. Note there are several potentials for the metal $U$ in the literature $[20,27-$ 29], but so far none of them has been applied to the $\beta U$ phase.

\subsubsection{3 $\gamma \mathrm{U}$ phase}

The bec $\gamma$-U phase is stable from $1045 \mathrm{~K}$ to the melting point of $1405 \mathrm{~K}$ [16]. The bcc structure can be viewed as the parent phase from which many of the high temperature actinide metal structures are derived, since many actinide metals also have a lowsymmetric bec phase [30] at high temperature.

For $\gamma \mathrm{U}$, the lattice constants are $3.47 \AA$ from experiment [25] at $298 \mathrm{~K}$. As listed in Table IV, the predicted lattice constants $a, b$, and $c$ are $3.474 \AA, 3.474 \AA$, and $3.474 \AA$, respectively. The cubic structure is kept upon a full relaxation and the deviation of the lattice constants from the experimental value is only $0.12 \%$. The corresponding error of the predicted volume $\left(41.927 \AA^{3}\right.$ per unit cell) from the experiment value $\left(41.782 \AA^{3}\right.$ per unit cell) is negligible, about $0.346 \%$.

The predicted potential energy is $-10.973 \mathrm{eV}$ for the 2-atom unit cell of the $\gamma \mathrm{U}$ phase, in reference to the target of $-10.339 \mathrm{eV}$. Correspondingly, the cohesive energies from prediction and the reference value are $-5.4865 \mathrm{eV} /$ atom and $-5.1695 \mathrm{eV} /$ atom, respectively. As a consequence, the cohesive energy is $0.0935 \mathrm{eV}$ higher with respect to the $\alpha \mathrm{U}$ phase and $0.0035 \mathrm{eV}$ lower with respect to the $\beta \mathrm{U}$ phase. This indicates the current unary $U$ potential may not be able to distinguish the phases between the $\beta U$ and $\gamma \mathrm{U}$ thermally at finite temperatures. The elastic constants are not tested for the $\gamma \mathrm{U}$ phase.

In an attempt to pursue the transferibility of the fitting potential in order to predict the correct structure stability for the three $U$ phases, the discrepancies of the predicted 
energy, lattice constants, and elastic constants from the reference data become worse. It is extremly difficult to maxiumize the transferibility and the accuracy of all phases. Some compromise to balance them may be necessary. Here the potential paramters for unary $U$ are chosen to give the correct cohesive energy, lattice constants and unit cell volume.

\section{Summary}

To allow for MD simulations on $\mathrm{U}_{3} \mathrm{Si}_{2}$ fuels, a Tersoff type bond-order U-Si interatomic potential is developed. Ideally, a good potential can be expected by force matching using data directly from DFT calculations. This has been recognized as a challenging task due to the complex crystal structure of U-Si phases, the lack of reference data and the difficulties in treating $5 f$ electrons (present in metal $U$ ) in the standard DFT calculations. As a result, it was determined that developing a force matching potential may not be feasible in a limited time, due to some suspicion on the validity of the force data generated by DFT calculations. Therefore, an alternative approach using the GULP software to directly fit the crystal structure, enthalpy of formation and elastic constants is adopted for the U-Si potential.

The U-Si potential developed here is based on the unary Si potential existing in the literature and a $U$ potential that is developed here. Two sets of parameters are obtained for U-Si systems using cross-term fitting (the cross-term potential) and the Tersoff mixing rules (the Tersoff mixing potential), respectively. Data from experiments and DFT calculations are used to fit and to assess the fitting results. While both potentials show satisfactory fitting results on the lattice constants and enthalpies of formations for $\mathrm{U}_{3} \mathrm{Si}_{2}$ and $\mathrm{U}_{3} \mathrm{Si}$ phases, the cross-term potential is found to be superior to the Tersoff mixing potential in all areas. The former also produces much better agreement with the literature data on the elastic constants of $\mathrm{U}_{3} \mathrm{Si}_{2}$. Therefore, the cross-term potential is likely to be the choice for possible further improvement.

The unary U potential developed here serves as the basis to obtain a U-Si potential, which is the primary focus. It reasonably reproduces the literature data on the lattice constants and cohesive energies of $(\alpha, \beta, \gamma)$-U phases, showing some transferibility of the potential. However, it fails to predict the right phase order between $\beta U$ and $\gamma \mathrm{U}$ with a negligible energetic difference between them. Therefore, it would hard for this potential to distinguish these two phases at finite temperatures. However, it's not clear if any phase transition will happen if a simulation starts with one of these two phases.

So far the potential fitting has been limited to some basic material properties of $\mathrm{U}_{3} \mathrm{Si}_{2}$. Lattice defects such as point defects, their clusters and interfaces have not been included. Part of the reason is that such data are mostly missing. These data will be used for further improvement or assessment once they are available.

As the potential shows encouraging results on the enthalpies of formation and crystal structures of some U-Si systems, a more rigorous test and further optimization are needed and planned as given in the following: 
1) The fitting is done using the software GULP with the calculated results generated by GULP also. The potential parameters will be tested using the popular MD simulation package LAMMPS [31] to assure robustness. Finite temperature, dynamic simulations are planned to make sure the phases predicted here are stable and to avoid surprising metastable phases.

2) The potential will be used to calculate the properties of simple defects such as point defects. The results will be compared with DFT results that are expected to be available soon. After finishing the point defects, the potential will also be tested on grain boundaries and interactions of point defects with grain boundaries. These calculations will be done at $0 \mathrm{~K}$. Dynamic simulations at finite temperatures will be tried after the $0 \mathrm{~K}$ static calculations are successful.

3) Further improvement of the binary U-Si potential and unary U potential with higher transferibility will occur.

4) A pair interaction term is planned to be added to the U-Si potential to include fission gas such as Xe. As Xe is an inert gas, the interaction between Xe and Xe is believed to be much easier to fit, and the interaction between $\mathrm{Xe}$ and $\mathrm{U}$ and that between Xe and Si might not be very difficult to fit. This work can be done in parallel with the optimization of the U-Si potential.

Finally, we wish to mention that under the ATF-HIP project there is another effort going on to develop a MEAM type U-Si potential utilizing the existing MEAM U and Si potentials to fit cross-term parameters, targeting a quick success. This task is led by David Andersson and Mike Baskas from Los Alamos National Laboratory and Ben Beeler from Idaho National Laboratory. A cross comparison will be done once both potentials are ready. That potential development has been documented elsewhere and is not included in this report. 


\section{References}

1. Zinkle, S.J., et al., Accident tolerant fuels for LWRs: A perspective. Journal of Nuclear Materials, 2014. 448(1-3): p. 374-379.

2. Kim, Y.S., et al., Temperature and dose dependence of fission-gas-bubble swelling in U3Si2. Journal of Nuclear Materials, 2009. 389(3): p. 443-449.

3. Birtcher, R.C., J.W. Richardson, and M.H. Mueller, Amorphization of U3Si2 by ion or neutron irradiation. Journal of Nuclear Materials, 1996. 230(2): p. 158-163.

4. Richardson, J.W., R.C. Birtcher, and S.K. Chan, Neutron irradiation induced amorphization of uranium silicides. Physica B, 1997. 241: p. 390-392.

5. Tersoff, J., Empirical interatomic potential for silicon with improved elastic properties. Physical Review B, 1988. 38(14): p. 9902-9905.

6. Tersoff, J., Modeling solid-state chemistry: Interatomic potentials for multicomponent systems. Physical Review B, 1989. 39(8): p. 5566-5568.

7. Kumagai, T., et al., Development of bond-order potentials that can reproduce the elastic constants and melting point of silicon for classical molecular dynamics simulation. Computational Materials Science, 2007. 39(2): p. 457-464.

8. Pastewka, L., et al., Screened empirical bond-order potentials for Si-C. Physical Review B, 2013. 87(20): p. 205410.

9. Schelling, P.K., Phase behavior and kinetics of a new bond-order potential for silicon. Computational Materials Science, 2008. 44(2): p. 274-279.

10. Ercolessi, F. and J.B. Adams, Interatomic Potentials from First-Principles Calculations: The Force-Matching Method. EPL (Europhysics Letters), 1994. 26(8): p. 583.

11. Gale, J.D., GULP: Capabilities and prospects. Zeitschrift Fur Kristallographie, 2005. 220(5-6): p. 552-554.

12. Gale, J.D. and A.L. Rohl, The General Utility Lattice Program (GULP). Molecular Simulation, 2003. 29(5): p. 291-341.

13. Remschnig, K., et al., Structural chemistry and magnetic behavior of binary uranium silicides. Journal of Solid State Chemistry, 1992. 97(2): p. 391-399.

14. Berche, A., et al., Thermodynamic study of the U-Si system. Journal of Nuclear Materials, 2009. 389(1): p. 101-107.

15. Wang, T., et al., First-principles investigations on the electronic structures of U3Si2. Journal of Nuclear Materials, 2016. 469: p. 194-199.

16. Armstrong, P.E., D.T. Eash, and J.E. Hockett, Elastic moduli of alpha, beta and gamma polycrystalline uranium. Journal of Nuclear Materials, 1972. 45(3): p. 211-216.

17. Lawson, A.C., et al., STRUCTURE OF BETA-URANIUM. Acta Crystallographica Section B-Structural Science, 1988. 44: p. 89-96.

18. Akella, J., et al., Structural stability in uranium. Journal of Physics-Condensed Matter, 1997. 9(39): p. L549-L555.

19. Okamoto, H., Si-U (Silicon-Uranium). Journal of Phase Equilibria and Diffusion, 2013. 34(2): p. 167-168.

20. Fernández, J.R. and M.I. Pascuet, On the accurate description of uranium metallic phases: a MEAM interatomic potential approach. Modelling and Simulation in Materials Science and Engineering, 2014. 22(5): p. 055019.

21. Barrett, C.S., M.H. Mueller, and R.L. Hitterman, Crystal Structure Variations in Alpha Uranium at Low Temperatures. Physical Review, 1963. 129(2): p. 625-629.

22. Kittel, C., Introduction to Solid State Physics. 1986: New York: Wiley Interscience.

23. Söderlind, P., First-principles elastic and structural properties of uranium metal. Physical Review B, 2002. 66(8): p. 085113. 
24. Fisher, E.S. and H.J. McSkimin, Low-Temperature Phase Transition in Alpha Uranium. Physical Review, 1961. 124(1): p. 67-70.

25. Wilson, A.S. and R.E. Rundle, THE STRUCTURES OF URANIUM METAL. Acta Crystallographica, 1949. 2(2): p. 126-127.

26. Yoo, C.-S., H. Cynn, and P. Söderlind, Phase diagram of uranium at high pressures and temperatures. Physical Review B, 1998. 57(17): p. 10359-10362.

27. Beeler, B., et al., Atomistic properties of gamma uranium. Journal of Physics-Condensed Matter, 2012. 24(7).

28. Li, Y., et al., Classical interatomic potential for orthorhombic uranium. Journal of Physics-Condensed Matter, 2012. 24(23).

29. Smirnova, D.E., S.V. Starikov, and V.V. Stegailov, Interatomic potential for uranium in a wide range of pressures and temperatures. Journal of Physics-Condensed Matter, 2012. 24(1).

30. Mettout, B., et al., Theory of reconstructive transformations in actinide elements: Packing of nonspherical atoms and macroscopic symmetries. Physical Review B, 1993. 48(10): p. 6908-6912.

31. S. Plimpton, Fast Parallel Algorithms for Short-Range Molecular Dynamics, J Comp Phys, 117, 1-19 (1995) 